\title{
ARTIKELEN
}

\author{
THEMA-ARTIKEL
}

\section{Decentraliseren en experimenteren}

\section{De ontwikkeling van sociaal beleid voor asielmigranten door gemeenten $^{*}$}

Rianne Dekker \& Meike Bokhorst

\section{Decentralisatie en verbreding van het integratiebeleid}

Op verschillende sociale beleidsterreinen spelen gemeenten een steeds belangrijkere rol. Dit geldt niet alleen voor taken die de afgelopen jaren gedecentraliseerd zijn zoals jeugdzorg, werk en inkomen en langdurige zorg. Ook op andere beleidsterreinen waar de problemen vooral op lokaal niveau tot uiting komen, nemen gemeenten de regie. Dit geldt niet in de laatste plaats voor het beleidsterrein van integratie en inburgering. De grotere verantwoordelijkheid van gemeenten op dit terrein wordt wel gezien als de vierde grote decentralisatie (Zapata-Barrero, Caponio \& Scholten, 2017). De eigen verantwoordelijkheid van de inburgeraar die het ministerie van Sociale Zaken en Werkgelegenheid sinds 2013 als uitgangspunt voor het beleid nam, heeft onvoldoende gewerkt (Algemene Rekenkamer, 2017). Met de nieuwe inburgeringswet krijgen gemeenten per 1 juli 2021 meer taken, bevoegdheden en middelen om de inburgering van nieuwkomers te verbeteren (TK 35483, nr. A). Een inburgeringstraject biedt inburgeringsplichtigen in de eerste twee jaar starthulp op het gebied van taal, onderwijs en werk. Inburgering is daarmee gericht op sociaaleconomische integratie van nieuwkomers.

Gemeenten krijgen te maken met bredere vraagstukken rond integratie en nemen ook zelf de regie op dit terrein. Zo zien we dat gemeenten vaak opstaan tegen uitzetting van uitgeprocedeerde asielzoekers uit hun gemeente, en dat ze voorzieningen bieden voor langdurig verblijvende vreemdelingen zonder verblijfsrecht die voorbij gaan aan de landelijke 'bed, bad, brood'-norm (Staring, 2015). Gemeenten lopen rond deze kwesties aan tegen de grenzen van nationaal en Europees beleid. Oomen (2019) stelt dat we moeten toewerken naar een lokaal vreemdelingenrecht en -beleid. Gemeenten zouden volgens haar veel meer ruimte

* Dr. R. Dekker is universitair docent en onderzoeker bij het departement Bestuurs- en Organisatiewetenschap van de Universiteit Utrecht. Zij doet onderzoek naar de invloed van nieuwe media in verschillende beleidsterreinen waaronder integratie en veiligheid. Dr. A.M. Bokhorst is senior wetenschappelijk medewerker bij de Wetenschappelijke Raad voor het Regeringsbeleid en onderzoeker bij de Universiteit Utrecht. Zij is als projectcoördinator migratiediversiteit en auteur betrokken bij WRR-publicaties over de immigratiesamenleving. 
moeten krijgen om desgewenst een eigen uitnodigings-, toelatings- en uitzettingsbeleid te voeren. De maatregelen die gemeenten ontwikkelen, zijn vooruitstrevend en worden soms later nationaal overgenomen (Dekker, Emilsson, Krieger \& Scholten, 2015). De 'bed, bad, brood-norm' is hier een voorbeeld van, maar ook de Rotterdamwet, die de vestiging van lage inkomens in reeds kwetsbare wijken uitsluit.

Als gevolg van immigratie krijgen gemeenten te maken met toenemende diversiteit van hun populatie. Het NIDI en CBS (2020) hebben in een bevolkingsprognose voor 2050 laten zien dat de bevolkingssamenstelling van Nederland mogelijk sterk zal veranderen van 4,2 miljoen inwoners met een migratieachtergrond in 2020 naar tussen de 5,3 en 8,4 miljoen in 2050. Ook de diversiteit van mensen met een migratieachtergrond wordt groter. De voor Nederland 'klassieke' migrantengroepen (mensen met een Indonesische, Surinaamse, Antilliaanse, Turkse of Marokkaanse achtergrond) vormen nu nog 40 procent van de bevolking met een migratieachtergrond, maar dit daalt tot een derde à een kwart. De helft of meer van de eerste of tweede generatie heeft in 2050 een arbeidsmigratieachtergrond. Dit zijn enerzijds migranten van binnen de EU, vaak afkomstig uit Polen, Bulgarije en Roemenië, maar ook uit landen daarbuiten, zoals China en India. Het aandeel mensen uit asiellanden in het Midden-Oosten en Afrika stijgt van 15 procent naar 20 of mogelijk 25 procent. Met de toenemende diversiteit van herkomstlanden, verblijfsduur en migratiemotieven is er sprake van 'superdiversiteit' (Vertovec, 2007).

Er bestaan grote verschillen in diversiteit van bevolkingssamenstelling tussen en binnen gemeenten. Waar sommige gemeenten weinig diversiteit kennen, zijn Amsterdam, Den Haag en Rotterdam 'majority minority cities' geworden: steden waar de groep inwoners zonder migratieachtergrond minder dan de helft van de bevolking uitmaakt. Ook kennen grote steden, voorsteden, expatgemeenten, provinciegemeenten, tuinbouwgemeenten en grensgemeenten verschillende typen diversiteit (Jennissen, Engbersen, Bokhorst \& Bovens, 2018). Omdat deze gemeenten te maken krijgen met verschillende beleidsproblemen, bijvoorbeeld op het gebied van huisvesting, taal en discriminatie, zoeken zij handelingsperspectieven die passen bij de specifieke diversiteitsvraagstukken waarmee zij te maken krijgen (VNG \& SZW, 2020).

Als gevolg van de Europese vluchtelingencrisis van 2015/2016 kregen Nederlandse gemeenten te maken met de komst van nieuwe groepen asielmigranten. Het Centraal Orgaan Asielopvang (COA) doet een beroep op gemeenten voor het vinden van nieuwe asielopvanglocaties. Ook moeten gemeenten vluchtelingen na verkrijging van een verblijfsvergunning passende woonruimte aanbieden volgens een landelijke taakstelling die wordt gemaakt door het COA. Veel asielmigranten komen terecht in sociaaleconomisch zwakke wijken waar de meeste corporatiewoningen staan. Deze wijken kennen een relatief hoog aandeel kwetsbare huishoudens met meervoudige problemen en achterstanden (Leidelmeijer, Frissen \& Van Iersel, 2020). De sociale mobiliteit van veel asielmigranten is beperkt doordat velen van hen een ongunstige arbeidsmarktpositie hebben en hun achterstand op andere groepen heel langzaam inlopen (Engbersen et al., 2015). Als 
gemeenten asielmigranten vestigen in dit soort wijken, dan vergt sociale integratie van bestaande en nieuwe wijkbewoners extra begeleiding.

De snel veranderende samenstelling van wijken, mede naar aanleiding van de komst van asielmigranten, kan tot verschillende problemen leiden. Hogere etnische diversiteit van wijken hangt samen met lagere ervaren buurtcohesie, minder gevoel van veiligheid en minder thuisgevoelens (Jennissen et al., 2018). In diverse wijken hebben inwoners minder contact met hun buurtgenoten (Putnam, 2007; Wessendorf, 2014). Bestaande bewoners ervaren verlies van zeggenschap, cultuur en identiteit door de vestiging van andere etnische groepen in hun wijk (Smeekes \& Mulder, 2016). Deze verliesgevoelens beperken zich niet alleen tot personen met een Nederlandse achtergrond. Ook mensen met een Surinaamse en Antilliaanse achtergrond voelen zich minder thuis in een buurt met een hoge diversiteit naar herkomst (Jennissen et al., 2018: 103). Sociaaleconomisch krachtige huishoudens trekken naar andere delen van de stad als ze daartoe de mogelijkheden hebben - mede uit gebrek aan geschikte koopwoningen binnen de wijk. Dit zorgt voor snel verloop in een wijk. Vooral de naoorlogse flatwijken zijn verworden tot anoniem doorgangshuis waarbij de sociale stijgers telkens plaatsmaken voor nieuwkomers. Door de aanzienlijke doorstroom is het lastig om het sociaal weefsel in de wijk op te bouwen en in stand te houden. Het kader over TilburgNoord illustreert dit.

\section{Kader: Geringe sociale samenhang in doorgangswijk in Tilburg-Noord}

'Een mens heeft afstand van anderen nodig én hun nabijheid: voor heremiet of bijenvolk zijn weinigen geboren. Op de Rossiniflat is nabijheid zó nadrukkelijk dat de afstand er met een zekere kracht bewaard wordt.' (Van Westerloo, 2015, p. 196). Journalist Gerard van Westerloo maakte in 1982 voor Vrij Nederland een reportage over het langs elkaar heen leven in een flat in de wijk Stokhasselt in Tilburg-Noord. Mensen hadden geen zin om anderen tegen het lijf te lopen. De ontwerper had zich de wijk utopisch voorgesteld. Het zou een 'ongelooflijk gezellige boel' worden. Maar het ruim opgezette stedenbouwkundige plan maakte plaats voor stadsverdichting. De gemeente moest immers nog meer mensen huisvesten.

Sinds de jaren negentig trokken middenklassengezinnen uit de wijk en werd de bevolkingssamenstelling gekenmerkt door een combinatie van relatief jonge gezinnen met een migratieachtergrond en relatief oude bewoners met een Nederlandse achtergrond (gegevens stadsmonitor, juni 2014). Inmiddels heeft 63 procent een migratieachtergrond en wonen er in Stokhasselt zo'n 188 nationaliteiten, waaronder veel asielmigranten. In het nabijgelegen AZC kwam rond 2009 de helft van de bewoners uit Somalië. Zodra ze een verblijfsvergunning kregen, vestigden velen zich in de wijk. De flats kregen bijnamen als 'Klein Mogadishu'. Bewoners klaagden over qat kauwende en handelende Somaliërs (Wittenberg, 2009).

Stokhasselt werd voor asielmigranten een doorgangswijk. Zo'n twintig procent van de Somaliërs vertrok binnen een jaar naar een andere wijk. $\mathrm{Na}$ 
hen kwamen Eritreeërs, Syriërs en Afghanen in de flats wonen. Het is de grote stedelijke armoedeparadox, aldus de Amerikaanse stadssocioloog Edward Glaeser. Een wijk die zorgt voor goede voorzieningen op het gebied van huisvesting, werk, onderwijs, welzijn en openbaar vervoer, zal een sociale liftfunctie vervullen (Bodelier, 2020). Deze groepen vertrekken en vervolgens zal een wijk die mensen een kans op vooruitgang biedt, weer nieuwe migrantengroepen aantrekken. De wijk bevordert de sociaaleconomische integratie op individueel niveau, maar de sociale binding op het niveau van de wijk blijft achter.

Dit themanummer bevat vier actuele onderzoeken naar beleid voor sociale integratie, acceptatie en binding van asielmigranten in Nederlandse gemeenten. Met welk beleid trachten gemeenten de integratie van vluchtelingen te stimuleren? Hoe kan het draagvlak voor de komst van nieuwe vluchtelingengroepen en voorzieningen (zoals AZC's) worden gewaarborgd? Hoe verloopt de sociale integratie van vluchtelingen met een verblijfsstatus (ook wel 'statushouders') in verschillende wijken? En wat zijn de resultaten van specifieke beleidsinterventies, zoals gemengde woonvormen? De bijdragen bevatten relevante lessen over flexibiliteit en innovatiekracht van gemeenten wanneer zij deels noodgedwongen, deels op eigen initiatief nieuw beleid voor asielmigranten ontwikkelen.

\section{Bijdragen aan dit themanummer}

In de eerste bijdrage analyseert Ilona van Breugel verschillen en overeenkomsten in het integratiebeleid van zestien Nederlandse gemeenten. Nadat het integratiebeleid in de jaren 2000 in veel gemeenten was afgebouwd, zijn gemeenten naar aanleiding van de vluchtelingencrisis weer een actief integratiebeleid gaan voeren. Sommige gemeenten konden hierbij teruggrijpen op bestaande beleidskaders voor diversiteits- of participatiebeleid. Vaak betrof dit gemainstreamd beleid (gericht op alle burgers). In dit beleid is naast sociaaleconomische integratie ook aandacht voor sociale binding tussen bevolkingsgroepen. Deze gemeenten streven proactief een eigen visie op diversiteit na. Gemeenten die integratiebeleid nieuw moesten ontwikkelen, kozen vaker voor doelgroepenbeleid voor nieuwe migranten, vaak specifiek gericht op sociaaleconomische integratie en expliciet tijdelijk van aard. Op die manier wordt specifieke ondersteuning geboden, bijvoorbeeld toeleiding tot de arbeidsmarkt. Deze tijdelijke vorm van ondersteuning is echter minder toegerust op blijvende fluctuaties en veranderingen in de bevolkingssamenstelling.

In de tweede bijdrage onderzoeken Rianne Dekker, Karin Geuijen en Caroline Oliver hoe de gemeente Utrecht de vestiging van een nieuw asielzoekerscentrum in Utrecht Overvecht heeft begeleid (het zogenoemde 'Plan Einstein') en hoe de acceptatie van dit AZC in deze wijk verliep. Buurtbewoners konden deelnemen aan cursussen en activiteiten die in het AZC werden aangeboden. Na hevige protesten bij de aankondiging van het AZC bleken buurtbewoners in surveys en 
interviews na de vestiging van het AZC aanmerkelijk positiever over het AZC. Dit was het gevolg van het uitblijven van verwachte negatieve effecten en niet een direct gevolg van het gevoerde beleid. Buurtbewoners die aan de cursussen en activiteiten deelnamen, stonden al overwegend positief tegenover het AZC en zijn bewoners. Voor sommigen veranderde Plan Einstein wel hun mening over het AZC. De acceptatie van het AZC werd vergroot door contact met asielzoekers dat binnen en buiten het project tot stand kwam. Door snelle wisselingen van asielzoekers in het AZC en doordat slechts een minderheid van de vluchtelingen met een verblijfsstatus zich in Utrecht kon vestigen, ontstond er 'publieke familiariteit' die niet uitgroeide tot sterkere sociale bindingen.

Meta van der Linden onderzoekt in welke mate de aanwezigheid van specifieke groepen in de buurt bijdraagt aan de sociale integratie van vluchtelingen met een verblijfsstatus in Rotterdam. Gemeenten streven er doorgaans naar om statushouders in verschillende buurten te huisvesten in de verwachting dat contact met inwoners van andere culturele achtergronden de integratie bevordert. Van der Linden vindt steun voor deze ontmoetingsmogelijkhedenhypothese: statushouders die wonen in een buurt met een groter aandeel buurtgenoten van Nederlandse afkomst, hebben vaker contact met buren met een Nederlandse afkomst. Voor contact met andere migrantengroepen kwam een complexer beeld naar voren. Syrische statushouders hebben vaker contact met mensen met een Marokkaanse afkomst, terwijl Eritrese statushouders geen gebruik maakten van deze ontmoetingsmogelijkheden. Dit is te verklaren vanuit de homofiliehypothese: groepen van Syrische en Marokkaanse afkomst die een gemeenschappelijke taal en cultuur delen, treden gemakkelijker met elkaar in contact. Hieruit concludeert Van der Linden dat ontmoetingsmogelijkheden met andere groepen in de buurt een noodzakelijke maar geen voldoende voorwaarde zijn voor het ontstaan van sociaal contact.

Ten slotte onderzoeken Carla Huisman en Darinka Czischke effecten van gemengd wonen in het Amsterdamse project Startblok Riekerhaven. In Nederland winnen projecten op het gebied van gemengd wonen met vluchtelingen aan populariteit. Het project met gedeelde voorzieningen en zelfbeheer focust op mix én concentratie van vluchtelingen en Nederlandse jongeren. Het onderzoek van Huisman en Czischke laat zien dat dergelijke projecten de vorming van sociale bindingen kunnen stimuleren. Zij betogen dat het nastreven van gemengd, geconcentreerd wonen belangrijk is en dat beleid voor huisvesting van vluchtelingen ten onrechte gescheiden is van integratie- en inburgeringsbeleid. Verder onderzoek moet uitwijzen op welke manier deze methode ook breder inzetbaar is, bijvoorbeeld voor andere doelgroepen dan jongvolwassenen.

Welke lessen voor gedecentraliseerd integratiebeleid kunnen we trekken uit deze bijdragen? En wat leert dit ons meer in het algemeen over innovatiekracht van gemeenten? In het navolgende leggen we parallellen tussen de vier bijdragen, gericht op drie onderwerpen: ten eerste betogen we dat gemeenten naast het bieden van lokaal maatwerk ook voorbereid moeten zijn op veranderingen als gevolg van veranderende en fluctuerende migratiestromen. Ten tweede bieden we een kritische bespreking van het beleid voor sociale binding in wijken: welk type 
contact tussen bevolkingsgroepen beogen gemeenten en waar hebben verschillende groepen bewoners baat bij? Ten derde gaan we in op de wijze waarop gemeenten vormgeven aan living labs en sociale experimenten en welke rol deze kunnen spelen in het opschalen van beleid.

\section{Decentralisatie van nood tot deugd maken}

Na de Europese vluchtelingencrisis van 2015/2016 bestond er voor gemeenten meer dan voorheen de ruimte om een eigen aanpak te ontwikkelen, passend bij het type diversiteit en daarmee gepaarde vraagstukken die zich in de gemeente voordoen. Dit past bij een van de centrale ideeën achter decentralisatie: lokaal maatwerk bieden (De Vries, 2000). Decentralisaties in het sociale domein hebben echter - mede onder druk van bezuinigingen - niet altijd goed uitgepakt. Verschillende gemeenten ervaren bijvoorbeeld grote problemen bij de uitvoering van de jeugdzorg en deze decentralisatie wordt gedeeltelijk teruggedraaid. Kleine gemeenten konden de gevraagde voorzieningen zelf moeilijk organiseren en de regionale samenwerking liet te wensen over.

De vluchtelingencrisis heeft het belang aangetoond om een basisinfrastructuur van voorzieningen en beleid in stand te houden om nieuwe groepen snel te kunnen inpassen op de woningmarkt, de arbeidsmarkt, in het onderwijs en de wijken. De bijdrage van Ilona van Breugel laat zien dat gemainstreamd beleid een algemeen geldende beleidsvisie op diversiteit en participatie - hiervoor wenselijk is. Het op- en afschalen van voorzieningen en het maken van ad-hoc-beleid voor specifieke doelgroepen gaan gepaard met hogere kosten en kennisverlies. Gemeenten moeten dan bij een toename van asielmigranten allemaal tegelijk voorzieningen tegen de hoogste prijs inkopen en beleidsmatig het wiel opnieuw uitvinden. Voor kleine gemeenten met beperkte budgetten is continuïteit van voorzieningen echter niet altijd haalbaar. Gemeenten kunnen voorzieningen dan op regionaal niveau ontwikkelen en in stand houden (Groenleer \& Verheul, 2017).

Zoals de casus van het Utrechtse Plan Einstein in de bijdrage van Rianne Dekker, Karin Geuijen en Caroline Oliver laat zien, is gemainstreamd beleid ook mogelijk bij urgente problematiek en specifieke doelgroepen. Toeleiding naar de arbeidsmarkt was niet alleen beschikbaar voor recente asielmigranten, maar ook voor andere bewoners uit Overvecht die aan de cursussen en activiteiten konden deelnemen. Het werken met deze gemengde groepen was niet altijd makkelijk: er speelden bijvoorbeeld taalbarrières en ervaren cultuurverschillen. Ondertussen bood dit gemainstreamde project wel mogelijkheden om op gelijkwaardige basis sociaal contact te leggen, een nevendoelstelling van het beleid.

\section{Een brede blik op contact en sociale binding}

Veel van de integratieprojecten in dit themanummer hebben sociale cohesie, binding of contact in wijken als beleidsdoel. Door toenemende diversiteit en wisseling van bewoners nemen gevoelens van verbondenheid af en kunnen spanningen 
toenemen tussen bewoners en met institutionele vertegenwoordigers zoals de politie of de gemeente. Buurten die al zwak waren, zijn door de komst van nieuwe kwetsbare groepen nog zwakker geworden. Volgens de koepel van woningcorporaties AEDES (2020) staan veel buurten op het punt te veranderen in probleemgebieden als we nu niet ingrijpen.

Gemeenten zetten bij de huisvesting van nieuwe migrantengroepen vaak in op spreiding over de stad. Het principe van gemengde wijken is stevig verankerd in de Nederlandse stads- en wijkontwikkeling. Zoals Meta van der Linden beschrijft, is het idee hierachter dat dit meer mogelijkheden tot ontmoeting van anderen genereert. Woningcorporaties hebben invloed op de sociale samenstelling van de wijk door het bouwen en renoveren van woningen en het herstructureren en transformeren van wijken. De studie van Meta van der Linden laat echter zien dat het creëren van ontmoetingsmogelijkheden met andere groepen door spreidingsbeleid een noodzakelijke, maar geen voldoende voorwaarde is voor het ontstaan van interetnisch contact.

Dit betekent dat gemeenten spreidingsbeleid zouden moeten aanvullen met beleid dat gericht is op het stimuleren van contact middels sociale activiteiten. De bijdragen van Dekker, Geuijen \& Oliver en Huisman \& Czischke onderstrepen dit. In Plan Einstein zorgden gezamenlijke cursussen en activiteiten voor een gelijkwaardige basis voor het leggen van contact. Bij Startblok Riekershaven waren de verantwoordelijkheid voor gedeelde ruimtes en zelfbeheer een doel waarvoor samenwerking vereist was. Samenwerken aan een gezamenlijke taak of doel beschreef Allport (1954) inderdaad als belangrijke voorwaarde voor het ontstaan van interetnisch contact.

Daarnaast is het opvallend dat verschillende projecten zich voornamelijk op contact van vluchtelingen met bewoners met een Nederlandse achtergrond richten. Verschillende bijdragen in dit themanummer laten zien dat dit niet de meest logische doelgroepen zijn, zeker niet in grote, diverse steden. Het onderzoek van Van der Linden laat zien dat nieuwe migranten gemakkelijker in contact komen met eerdere migrantengroepen waarmee zij taal en cultuur delen. Ook in het onderzoek van Dekker, Geuijen en Oliver bleken buurtbewoners met een migratieachtergrond oververtegenwoordigd in de cursussen die bij het AZC werden aangeboden. Het programma, dat gericht was op de oriëntatie op de arbeidsmarkt en dat geschikt was voor anderstaligen, sprak deze groep in het bijzonder aan. Deze onderzoeken laten zien dat Nederlanders met een migratieachtergrond een belangrijke brugfunctie kunnen vervullen in de kennismaking van nieuwe migranten met de bredere Nederlandse samenleving.

\section{Living labs: meer lokale ruimte voor experimenteren en investeren}

Plan Einstein in Utrecht, Startblok Riekerhaven in Amsterdam en het project 'Stichting Nieuw Thuis Rotterdam', waarnaar het EUR Bridge-project onderzoek doet, zijn alle drie voorbeelden van beleidsexperimenten die moeten leiden tot een nieuwe strategie voor de integratie van vluchtelingen. Het ontstaan hiervan is niet toevallig. De vluchtelingencrisis van 2015/2016 en het beleidsvacuüm op 
nationaal niveau boden gemeenten de mogelijkheid om nieuw beleid te ontwikkelen en te testen. Hierbij zijn meestal verschillende partijen betrokken: de gemeente zelf, sociaal ondernemers en kennisinstituten die hun kennis, vaardigheden en netwerk voor dit thema willen inzetten. Door de urgentie van de problematiek worden beleidsoplossingen al gaandeweg ontwikkeld en direct in de sociale werkelijkheid getest. De drie projecten die in dit themanummer zijn beschreven, zijn op te vatten als living labs (Dekker, Franco Contreras \& Meijer, 2019).

Waar living labs hun oorsprong hebben in ICT, denk bijvoorbeeld aan slimme energiemeters in huizen en smart city-toepassingen in steden, worden zij nu steeds vaker ingezet voor sociale en publieke innovatie (Bergvall-Kåreborn \& Ståhlbröst, 2009; Karré, Vanhommerig \& Van Buuren, 2015). Het ontwikkelen en testen van een nieuwe oplossing in de context waarin ze toegepast gaan worden, is een generatieve vorm van experimenteren (Ansell \& Bartenberger, 2016). Juist voor complexe problematiek waarvoor geen bewezen beleidsoplossingen bestaan, zoals integratie, zijn living labs van meerwaarde. Publieke en private partners kunnen met een belangrijke feedbackrol voor de 'eindgebruiker' zoeken naar innovatieve oplossingen. Met living labs kunnen gemeenten passend sociaal beleid ontwikkelen op wijkniveau waar zich problemen voordoen.

Een belangrijke uitdaging blijft om van experimenten tot duurzaam beleid te komen. Het blijkt lastig om de geleerde lessen en succesfactoren uit individuele projecten op te schalen naar structurele aanpakken in lokaal of regionaal beleid. Beleidsaandacht verslapt vaak als de ergste problemen verholpen zijn of de pilotfase met bijbehorende financiering voorbij is. Door stedelijke beleidsexperimenten te evalueren op basis van condities waaronder de interventie is ontwikkeld en functioneert en zo de mogelijkheden tot opschalen te onderzoeken, kunnen gemeenten binnen gedecentraliseerde beleidsdomeinen een katalysatorfunctie vervullen bij de ontwikkeling van nieuw beleid. Juist bij deze kennisontwikkeling en -deling is ook een belangrijke rol weggelegd voor het ministerie van Sociale Zaken in samenwerking met de Vereniging van Nederlandse Gemeenten.

Er moet niet alleen aandacht zijn voor nieuwe initiatieven, maar ook voor de inbedding van nieuwe initiatieven in bestaand beleid in wijken. Integratie en sociale samenhang vragen om stevige sociale voorzieningen die nu juist door de afgelopen decentralisatierondes deels zijn ingeperkt of beëindigd. Dat vluchtelingen zich voornamelijk vestigen in sociaal zwakke wijken, is het gevolg van beleid waardoor de sociale woningvoorraad is afgenomen en geconcentreerd. Ook het snelle verloop in deze wijken kan worden toegeschreven aan beleid om de woningmarkt 'van het slot' te halen door bijvoorbeeld scheefwonen aan te pakken. Beleid voor binding van asielmigranten in superdiverse wijken kan alleen slagen als gemeenten het woonbeleid hiermee in samenhang brengen. Naast goede woonfaciliteiten zijn jeugdzorg, psychische zorg en schuldhulp belangrijk voor asielmigranten, die zich vaak in kwetsbare maatschappelijke posities bevinden. De fysieke aanwezigheid van pleintjes, parkjes, speeltuintjes, bankjes en een stads- of wijkhart helpt om de publieke familiariteit te vergroten. Verder zijn faciliteiten als bibliotheken, zwembaden en toegankelijke sociale loketten van belang als laagdrempelige manieren om in contact te komen met de omgeving en de overheid. 
Ook daar is de afgelopen jaren op bezuinigd, vooral in de kleinere en middelgrote gemeenten. Als gemeenten niet kunnen investeren, verdwijnt ook het animo om te experimenteren.

\section{Literatuur}

AEDES. (2020). 'Achterstandswijken' terug in Nederland? Geraadpleegd op 22 juli 2020 van www.aedes.nl/artikelen/klant-en-wonen/wijkaanpak-en-leefbaarheid/leefbaarheid/ aedes-achterstandswijken-terug-in-nederland.html

Algemene Rekenkamer. (2017). Inburgering: De eerste resultaten van de Wet inburgering 2013. Den Haag: Algemene Rekenkamer.

Allport, G.W. (1954). The nature of prejudice. Reading, MA: Addison-Wesley.

Ansell, C.K., \& Bartenberger, M. (2016). Varieties of experimentalism. Ecological Economics, 130, 64-73.

Bergvall-Kåreborn, B., \& Ståhlbröst, A. (2009). Living Lab: an open and citizen-centric approach for innovation. International Journal of Innovation and Regional Development, 1(4), 356-370.

Bodelier, R. (2020). Hart van Brabant \#6: Een flat in Tilburg-Noord: De grote stedelijke armoedeparadox. De Groene Amsterdammer, 29 juni.

Dekker, R., Emilsson, H., Krieger, B., \& Scholten, P. (2015). A local dimension of integration policies? A comparative study of Berlin, Malmö, and Rotterdam. International Migration Review, 49(3), 633-658.

Dekker, R., Franco Contreras, J.F., \& Meijer, A.J. (2019). The living lab as a methodology for public administration research: A systematic literature review of its applications in the social sciences. International Journal of Public Administration, 43(14), 1207-1217.

Engbersen, G., Dagevos, J., Jennissen, R., Bakker, L., Leerkes, A., Klaver, J., \& Odé, A. (2015). Geen tijd verliezen: van opvang naar integratie van asielmigranten. Den Haag: WRR.

Groenleer, M., \& Verheul, W.J. (2017). Regiovorming: Tussen inhoud en institutionalisering. Bestuurskunde, 26(2), 3-10.

Jennissen, J. Engbersen, G., Bokhorst, M., \& Bovens, M. (2018). De nieuwe verscheidenheid: Toenemende diversiteit naar herkomst in Nederland (WRR-verkenning nr. 39). Den Haag: WRR.

Karré, P., Vanhommerig, I., \& Buuren, E. van. (2015). De stad als lab voor sociale verandering. Bestuurskunde, 24(1), 3-11.

Leidelmeijer, K., Frissen, J. \& Van Iersel, J. (2020). Rapport Veerkracht in het corporatiebezit. De update: Een jaar later, twee jaar verder... In Fact/Rigo i.o.v. AEDES.

NIDI \& CBS. (2020). Bevolking 2050 in beeld: drukker, diverser en dubbelgrijs. Den Haag: NIDI.

Oomen, B.M. (2019). Naar een lokaal vreemdelingenrecht en -beleid. Journaal Vreemdelingenrecht, 3(1), 17-24.

Putnam, R.D. (2007). E pluribus unum: Diversity and community in the twenty-first century: The 2006 Johan Skytte prize lecture. Scandinavian Political Studies, 30(2), 137-184.

Smeekes, A., \& Mulder, L. (2016). Verliesgevoelens in relatie tot de multi-etnische samenleving onder autochtone Nederlanders. Den Haag: Wetenschappelijke Raad voor het Regeringsbeleid. 
Staring, R. (2015). Niemand slaapt bij ons op straat? Over de noodopvang van onrechtmatig verblijvende vreemdelingen en het steekspel tussen centrale overheid en gemeenten. Justitiële Verkenningen, 41(2), 24-38.

Tweede Kamer. (2020, 2 juli). Wet inburgering. Kamerstuk 35483, nr. A.

Vertovec, S. (2007). Super-diversity and its implications. Ethnic and Racial Studies, 30(6), 1024-1054.

VNG \& SZW. (2020). De Nieuwe Verscheidenheid: Handelingsperspectieven voor lokale bestuurders. Den Haag: Vereniging van Nederlandse Gemeenten.

Vries, M.S. de. (2000). The rise and fall of decentralization: A comparative analysis of arguments and practices in European countries. European Journal of Political Research, 38(2), 193-224.

Wessendorf, S. (2014). Being open, but sometimes closed: Conviviality in a super-diverse London neighbourhood. European Journal of Cultural Studies, 18(4), 392-405.

Westerloo, G. van. (2015). De pont van kwart over zeven: De beste journalistieke verhalen. Amsterdam: De Bezige Bij.

Wittenberg, E. (2009, 29 december). Van groene droombuurt tot klein Mogadishu. NRC Handelsblad, p. 2.

Zapata-Barrero, R., Caponio, T., \& Scholten, P. (2017). Theorizing the 'local turn' in a multi-level governance framework of analysis: A case study in immigrant policies [special issue]. International Review of Administrative Sciences, 83(2), 225-422. 